\title{
FEM-based research on the dynamic response of a concrete railway arch bridge
}

\author{
Chao Wang, Zhilan Wang, Jiwen Zhang and Yongming Tu \\ Southeast University, Nanjing, PR China \\ Niklas Grip, Ulf Ohlsson and Lennart Elfgren \\ Luleå University of Technology, Luleå, Sweden \\ Contact: 838229678@qq.com
}

\begin{abstract}
The dynamic response of a concrete railway arch bridge is studied through a case study of the bridge over Kalix River, situated at Långforsen on the railway line between Kalix and Morjärv in northern Sweden. A simplified beam-element model, a spatial grillage-beam model and a refined shell-element model were built to analyze the bridge structure. A methodology was applied where measured static and dynamic responses were used to update finite element models of Långforsen Bridge. A multi-response objective function was presented, and the finite element method was proved feasible by comparison of predicted and measured response. In the paper comparative analyses were made of the time history displacement of three finite element models under three measured load cases. A standard train model from EUROCODE, HSLM-A 1, was applied and the dynamic responses under different speeds were studied. The results showed that a refined shell element model could accurately analyze dynamic responses of the concrete railway arch bridge in a better way than beam element and spatial grillage models. The dynamic analysis based on this type of shell model can give an optimized suggestion for the railway operation as well as for the design of high-speed railway bridges.
\end{abstract}

Keywords: Refined shell element model; Dynamic response; Moving load; Concrete railway arch bridge.

\section{Introduction}

Finite element method (FEM) is an achievement through comprehensive development and integration of multiple disciplines such as mechanics, mathematical physics, computational science, and computer technology, etc. It is a numerical simulation and analysis method used for structural analysis of large-scale structural projects which has been widely implemented in computer programs based on theory of structural mechanics and elasticity, and its application ranges from linear to non-linear, from static to dynamic [1].

Nowadays, there is a need to extend the life and capacity of many existing bridges, considering maintenance, upgrading, repair, and replacement 
of bridges lead to high costs and considerable disruption of traffic operation [2], FEM is becoming a popular method to support effective bridge management, accurate and reliable information about the safety and condition of bridges. According to the results of analysis and study, the reinforcement scheme is modified and optimized, the safety of existing bridges being judged and causes of engineering accident being analyzed. This method features mathematically rigorous logic and physically clear concept, and can flexibly handle complicated problems using computer-based programming [3].

In this paper, the author established finite element models according to the example of a concrete railway arch bridge, Långforsen Bridge, and updated these models using measured data for researching on the dynamic performance.

\section{Target Bridge}

\subsection{Background}

Långforsen Bridge is a concrete railway arch bridge over Kalix River, situated at Långforsen on the railway line between Kalix and Morjärv in northern Sweden, connected to the older Haparanda line, see Figure 1.

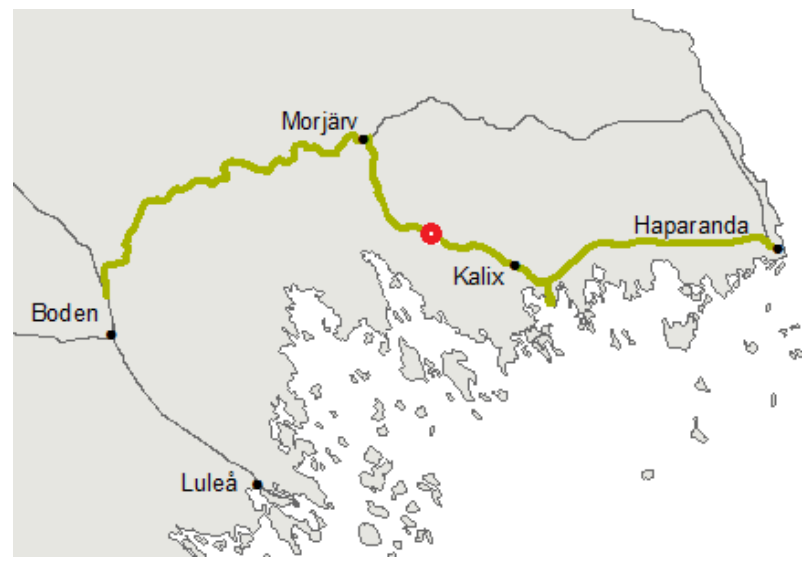

Figure 1. The bridge over Kalix River is situated at Långforsen some $10 \mathrm{~km}$ north-east of Kalix. The location is marked with a red dot.

The bridge owner, Trafikverket, wanted to assess the health-state, and then field tests were carried out under service condition and with ambient vibrations. The test results were used to update and validate Finite Element Models. At last, the refined models were used to research on dynamic performance of Långforsen Bridge and subsequent health monitoring.

Långforsen Bridge was designed by Uno Nordstrand at Kungliga Järnvägsstyrelsen during 1956-58 and built in 1960 by Nya Asfalt AB, has a total length of $177.3 \mathrm{~m}$ with a central arch of 89.5 $\mathrm{m}$ and two side spans of $42 \mathrm{~m}$, see details in Figure 2.

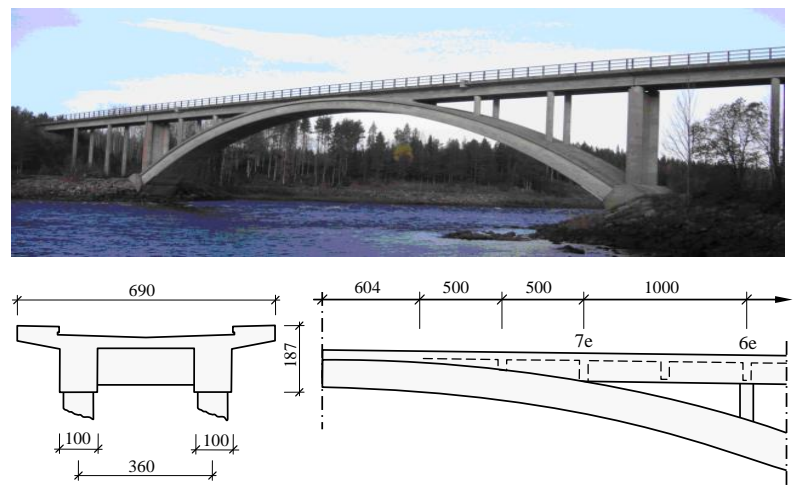

Figure 2. Elevation and Dimension drawing of Långforsen Bridge

\subsection{Finite Element Modelling}

A model is a numerical representation which carries out capacity evaluation and response analysis of structures, and finite element modeling is to discretize continuous structure into finite elements. The author used simplified beamelement model, spatial grillage-beam model and shell element model to simulate Långforsen Bridge respectively through commercial software, ABAQUS, based on the design drawings and related calculation documents, models as shown in Figure 3.

Among these models, simplified beam-element model adopted three-dimensional beam elements which are assigned by calculated cross section properties; spatial grillage-beam model was established with equivalent grillage-beam through dividing bridge structure into several segments, and flexural stiffness and torsional stiffness of deck and girder in each segment are concentrated in the equivalent grillage-beam. The longitudinal stiffness of actual structure is concentrated in longitudinal grillage-beam members and transverse stiffness in transverse members, and cross section properties are assigned in the 
corresponding three-dimensional beam elements; Shell element model is a refined bridge model that main parts of the bridge are simulated by shell elements, columns by three-dimensional beam elements and track structure with ballast by mass points, which reflects bridge characteristics intuitively and comprehensively. These three models all adopted the spring element to simulate foundations, and its stiffness determined by code calculation.

There are 780 elements in the simplified beamelement model, 4997 elements in the spatial grillage-beam model and 93910 elements in the refined shell-element model. Significantly increased element number of refined models sacrifices some computational efficiency.

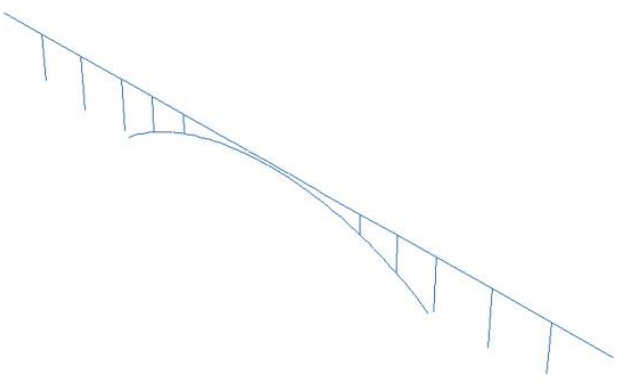

(a) Simplified beam-element model

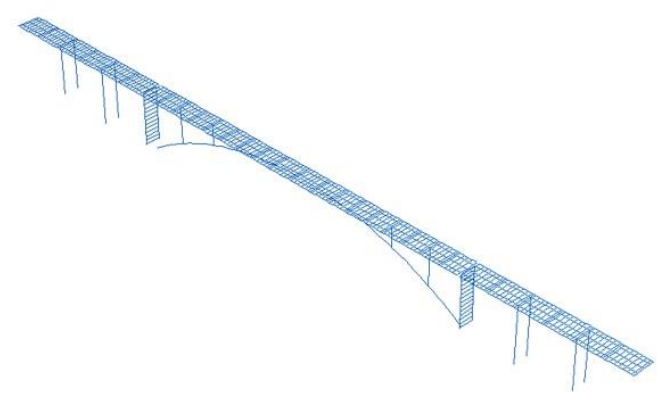

(b) Spatial grillage-beam model

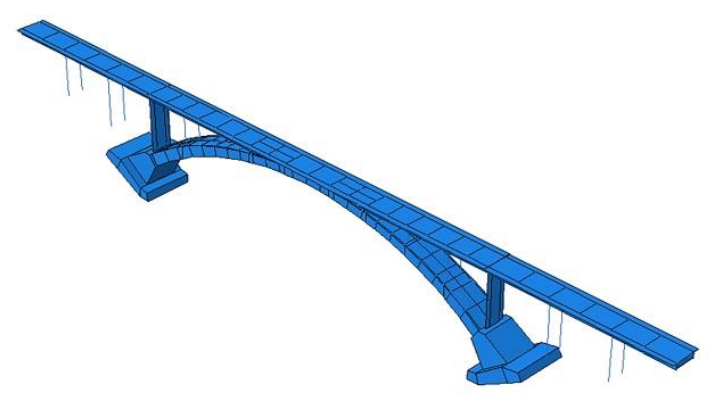

(c) Refined shell-element model
Figure 3. Three type FE models of Långforsen Bridge

\subsection{Model Updating}

To obtain dynamic responses of Långforsen Bridge under train loading directly and verify the accuracy of FE models, on-site measurements were carried out in and earlier project, Sustainable Bridge [4], under cooperation with Sweden Railway Bureau and Luleå University of Technology (LTU), Sweden. And for measuring dynamic performance comprehensively, different load cases were adopted, see details in Table 1 and Figure 4.
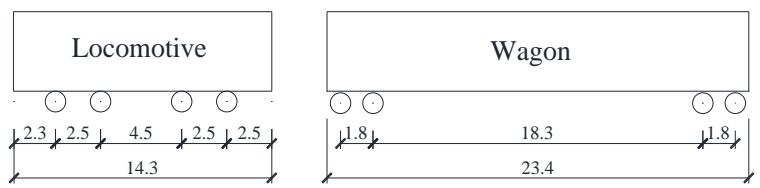

Figure 4. Geometric dimensions of train in operation (Unit: $m$ )

Table 1. Load Case

\begin{tabular}{c|c|c}
\hline $\begin{array}{c}\text { Load } \\
\text { Case }\end{array}$ & Train Marshalling & $\begin{array}{c}\text { Speed } \\
(\mathrm{km} / \mathrm{h})\end{array}$ \\
\hline 1 & 1 Locomotive + 2 Wagons & 58.5 \\
\hline 2 & 1 Locomotive + 7 Wagons & 41.2 \\
\hline 3 & 1 Locomotive + 13 Wagons & 28.4 \\
\hline
\end{tabular}

FE models are expressed as parameters, and updating process is to optimize structural parameters. Above three FE models were updated using dynamic responses and eigenfrequencies by dimensionless objective function in the form of sum of relative difference,

$$
f(x)=\sum_{j=1}^{n} \frac{x_{a j}-x_{e j}}{x_{e j}}
$$

$j \in[1, \mathrm{n}]$, where $\mathrm{x}_{a j}$ and $\mathrm{x}_{e j}$ are analysis and experimental response of $j_{t h}$ time or position point, respectively, $\mathrm{n}$ is the number of measured 
response. There are also another objective functions being adopted, Sanayei [5] and Q.W.Zhang [6] introduced another forms, see also [2]. Objective function exactly reflects the difference between prediction of the FE model and measured data, and optimization process is to minimize function value, and then model updating is transformed to be structural parameter optimization issue that using dynamic testing. J M.W. Brownjohn et al. [7] and Erin Santini Bell [8], etc. have done much research work on this issue.

The choice of parameter is the determinants for updating, in this case three structural parameters were selected through sensitivity analysis, and the formulation is

$$
s=\frac{\partial \lambda}{\partial p}
$$

where $\lambda$ is a eigenvalue and $p$ is a model parameter. The specific sensitivity analysis process can follow [9], [10] and [11] as well. And above analysis reveals that modulus of elasticity, $E_{\mathrm{c}}$, boundary condition (Soil deformation modulus),
$E_{s}$, and density of main structure, $\rho_{\mathrm{c}}$, have relative higher sensitivity. Then these parameters were chosen to be updated, detailed value of parameters are listed in Table 2. Above updating process was based on manual optimization, and the dynamic analysis results of FE models using updated parameters show good agreement with experimental results, as shown in Table 3. For further optimization of selected parameters, Niklas Grip et al have done much research, and a more complete description of automatic updating was introduced in [9].

Table 2. Parameters before and after updating

\begin{tabular}{c|c|c}
\hline Parameter & Initial Value & Updated Value \\
\hline$E_{\mathrm{c}}$ & $32500 \mathrm{MPa}$ & $39800 \mathrm{MPa}$ \\
\hline$E_{s}$ & $25 \mathrm{~kg} / \mathrm{cm}^{3}$ & $12 \mathrm{~kg} / \mathrm{cm}^{3}$ \\
\hline$\rho_{\mathrm{c}}$ & $2.6 \mathrm{t} / \mathrm{m}^{3}$ & $2.48 \mathrm{t} / \mathrm{m}^{3}$ \\
\hline
\end{tabular}

Table 3. Predicted and Measured Modes

\begin{tabular}{c|c|c|c|c|c|c|c}
\hline \multirow{2}{*}{ Order } & \multirow{2}{*}{$\begin{array}{c}\text { Measured } \\
\text { Frequency }\end{array}$} & \multicolumn{2}{|c|}{ FE Model (a) } & \multicolumn{2}{c|}{ FE Model (b) } & \multicolumn{2}{c}{ FE Model (c) } \\
\cline { 3 - 8 } & $(\mathrm{Hz})$ & Value & Error & Value & Error & Value & Error \\
$(\mathrm{Hz})$ & $(\%)$ & $(\mathrm{Hz})$ & $(\%)$ & $(\mathrm{Hz})$ & $(\%)$ \\
\hline 1 & 1.790 & 1.7847 & 0.296 & 1.7928 & 0.156 & 1.7819 & 0.450 \\
\hline 2 & $\mathrm{~N} / \mathrm{A}$ & 2.4363 & $\mathrm{~N} / \mathrm{A}$ & 2.5475 & $\mathrm{~N} / \mathrm{A}$ & 2.5528 & N/A \\
\hline 3 & 3.184 & 3.3918 & 6.526 & 3.0886 & 2.996 & 3.1697 & 0.449 \\
\hline 5 & 3.436 & 4.0502 & 17.875 & 3.4332 & 0.081 & 3.5023 & 1.930 \\
\hline 6 & 4.158 & 4.3589 & 4.832 & 4.1437 & 0.344 & 4.2924 & 3.232 \\
\hline 7 & 5.015 & 5.7646 & 19.947 & 5.2969 & 5.621 & 5.0425 & 0.548 \\
\hline & 5.964 & 6.0087 & 0.749 & 5.8357 & 2.151 & 5.8469 & 1.963 \\
\hline
\end{tabular}


Through above analysis, it can be found that there exists error between measurement and prediction. On the one hand, parameters need to be further updated, on the other hand the proposal of linearly elastic hypothesis when create FE models of Långforsen Bridge, but cannot completely meet the linear elastic assumption due to inevitable micro-flaws of actual bridge structure. FE models can only be continuously refined to be close to actual conditions but cannot completely reflect status of the bridge structure. In general, refined FE model can make a reasonable prediction of static/dynamic responses under train loading roughly.

\section{Dynamic analysis}

\subsection{Dynamic displacement at mid-span position}

Displacement of bridge's' key position is one of the most intuitive dynamic response under train loading. Vertical vibration of bridge structure needs to be limited, one reason is for riding stability and safety of train and the other is for guarantee that members or whole structure of bridges don't destroyed because of large vertical displacement under live load. EUROCODE [1] determined deflection limits of the bridge according to the requirements of the ride comfort at different speeds.

Generally mid-span position is the critical control point of bridge structures' vertical displacement according to structural and train load characters. Train dynamic deflections of mid-span position of Långforsen Bridge's three FE models under three load cases are summarized as Figure 5 (a) (c).

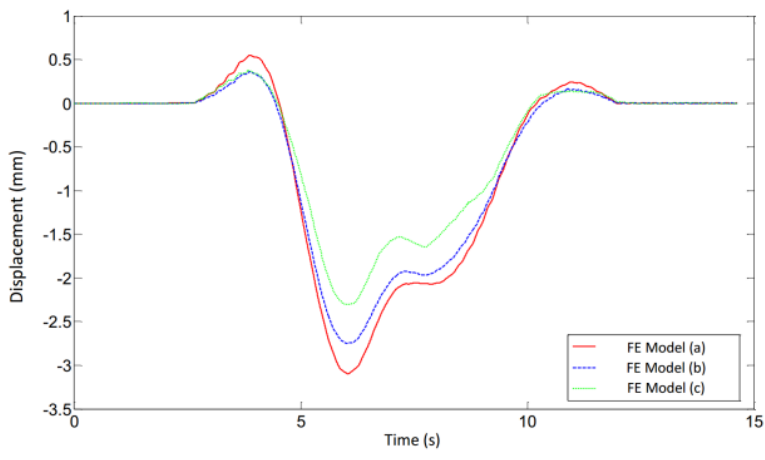

(a) Load Case 1

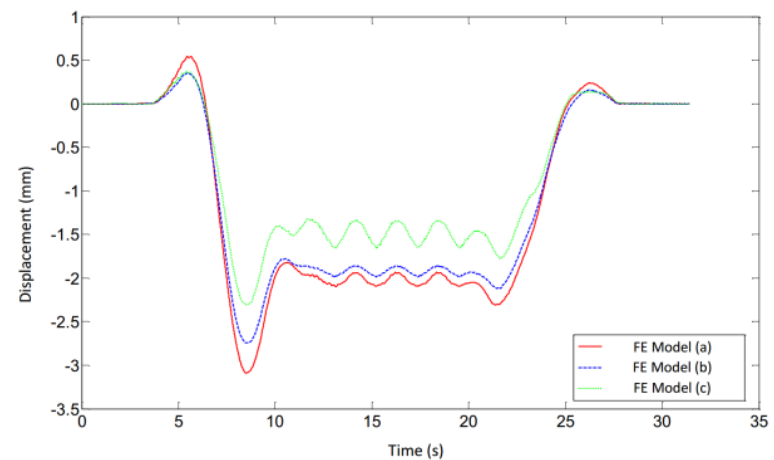

(b) Load Case 2

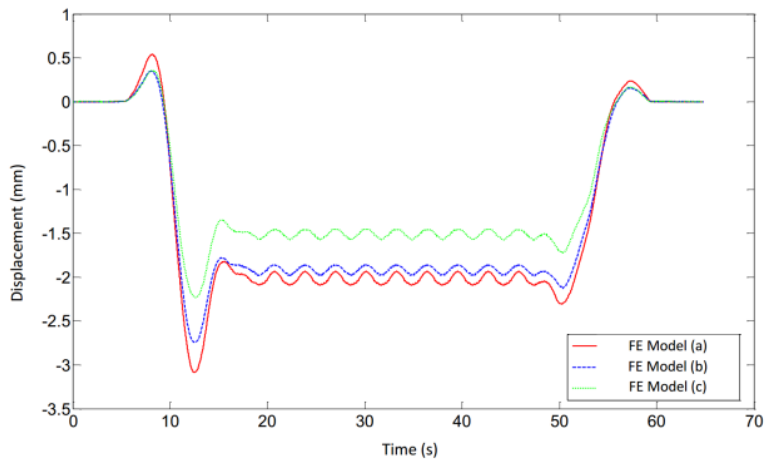

(c) Load Case 3

Figure 5. Dynamic displacement of mid-span position under three load cases

As seen in the above figures, the maximum vertical displacement of mid-span position under three speeds is basically equivalent, it is because that speeds are all relative low though different. The comparisons show that results of three FE models have the same order of magnitude at same speed: mid-span displacement of simplified beam-element model is maximum, spatial grillagebeam model takes the second and of refined shellelement is minimum. The reason is that spatial interaction of simplified beam-element model is worst of three FE models owing to simplification of girder; spatial grillage-beam model discretizes bridge deck and use equivalent grillage beam to simulate whole structure, spatial interaction of spatial grillage-beam model is weaker than of refined shell-element model although stronger than of simplified beam-element model.

One purpose of experimental study on Långforsen Bridge is to verify the validity, accuracy and reliability of FE model, and to obtain benchmark model, and then to predict dynamic responses of bridge under load-added and speed-increased 
conditions based on benchmark model. It can be seen that simplified beam-element model has maximum error from above analysis of measurement and prediction. But three FE models are in agreement with actual bridge well relatively so could be considered as reliable models for further analysis.

\subsection{Extended analysis}

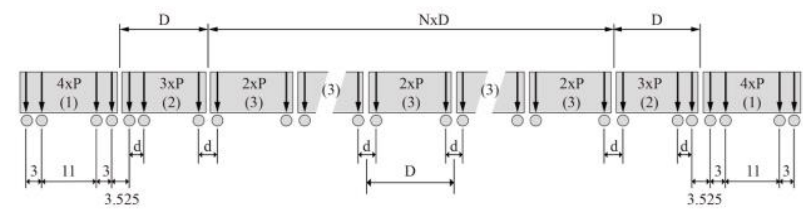

Figure 6. Geometric dimension of HSLM-A

In order to calculate dynamic responses of Långforsen Bridge under higher-speed train loading, a standard train model, HSLM-A [9], of EUROCODE is adopted. Figure 6 shows specific geometric dimension of HSLM-A. There are ten types of train formation, and here takes the first type as an example. The basic parameters are as follows: number of carriage, $\mathrm{N}=18$; length of carriage, $D=18 \mathrm{~m}$; axis spacing of bogies, $d=2.0 \mathrm{~m}$; axle load, $\mathrm{P}=170 \mathrm{kN}$. Train speed ranges from $150 \mathrm{~km} / \mathrm{h}$ to $350 \mathrm{~km} / \mathrm{h}$, and is divided into 21 variables at growth rate of $10 \mathrm{~km} / \mathrm{h}$.

The maximum acceleration and maximum displacement of mid-span position under different train speed are presented in Figure 7 and Figure 8.

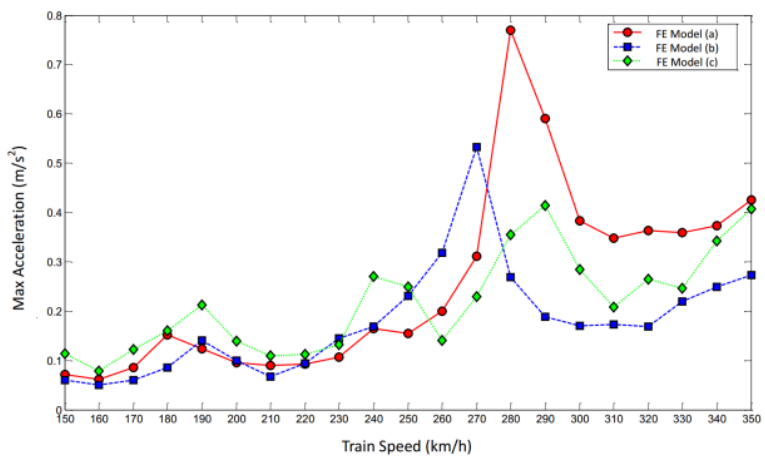

Figure 7. Maximum acceleration of mid-span

position

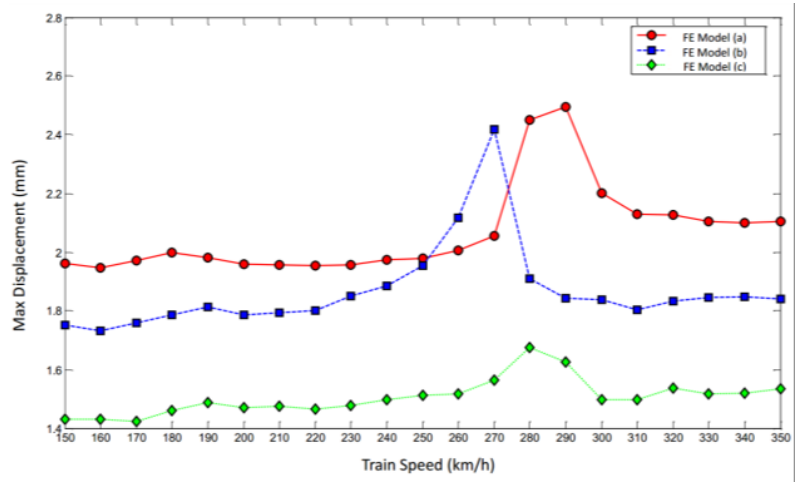

Figure 8. Maximum displacement of mid-span position

According to above figures, analysis results of three FE models have the same order of magnitude and general trend, and the maximum displacement and maximum acceleration are neither generated at peak speed, $350 \mathrm{~km} / \mathrm{h}$.

Maximum vertical accelerations at mid-span position are respectively:

(1) generated at $280 \mathrm{~km} / \mathrm{h}$ of the simplified beamelement model; The maximum acceleration at $275 \mathrm{~km} / \mathrm{h}$ and $285 \mathrm{~km} / \mathrm{h}$ are $0.4717 \mathrm{~m} / \mathrm{s}^{2}$ and $0.7578 \mathrm{~m} / \mathrm{s}^{2}$ respectively, and are both less than $0.7693 \mathrm{~m} / \mathrm{s}^{2}$ at $280 \mathrm{~km} / \mathrm{h}$, so that maximum acceleration is generated at the vicinity of $280 \mathrm{~km} / \mathrm{h}$.

(2) generated at $270 \mathrm{~km} / \mathrm{h}$ of the refined shellelement model by preliminary determination; The maximum acceleration at $265 \mathrm{~km} / \mathrm{h}$ and $275 \mathrm{~km} / \mathrm{h}$ are $0.4667 \mathrm{~m} / \mathrm{s}^{2}$ and $0.3767 \mathrm{~m} / \mathrm{s}^{2}$ respectively, and are both less than $0.5323 \mathrm{~m} / \mathrm{s}^{2}$ at $290 \mathrm{~km} / \mathrm{h}$, so that maximum acceleration is generated at the vicinity of $290 \mathrm{~km} / \mathrm{h}$.

(3) generated at $290 \mathrm{~km} / \mathrm{h}$ of the refined shellelement model by preliminary determination; The maximum acceleration at $285 \mathrm{~km} / \mathrm{h}$ and $295 \mathrm{~km} / \mathrm{h}$ are $0.4526 \mathrm{~m} / \mathrm{s}^{2}$ and $0.3265 \mathrm{~m} / \mathrm{s}^{2}$ respectively, and are both less than $0.4142 \mathrm{~m} / \mathrm{s}^{2}$ at $290 \mathrm{~km} / \mathrm{h}$, so that maximum acceleration is generated at the vicinity of $290 \mathrm{~km} / \mathrm{h}$.

Neither of maximum displacements is generated at peak speed as the maximum acceleration, and among three FE models the simplified beam- 
element model generated at $290 \mathrm{~km} / \mathrm{h}$ and its value is $2.4861 \mathrm{~mm}$; the value of spatial grillagebeam is $2.4177 \mathrm{~mm}$ at $270 \mathrm{~km} / \mathrm{h} ; 1.6752 \mathrm{~mm}$ at $280 \mathrm{~km} / \mathrm{h}$ of the refined shell-element model.

Basic principles of dynamics indicate that resonance will be produced when the mode frequency and excitation frequency come closer, and then causes excessive dynamic responses. For train-bridge system, train load is moving so that excitation frequency varies when train speed changes, thus dynamic responses of bridge structure also make differences. Dynamic response of bridge structure is the most intense when load frequency is more close to eigenfrequency.

Therefore, assessment of bridge bearing capacity can not only focus on the maximum train speed, but also another speed condition to avoid from that load frequency of moving train close proximity with eigenfrequency of the bridge structure at non-maximum speed and induce excessive dynamic responses or even resonance phenomenon.

\section{Conclusions}

This paper firstly constructs a simplified beamelement model, spatial beam-grillage model and shell-element model of a concrete arch railway bridge, Långforsen Bridge, and then updates these three FE models using measured dynamic responses to get more refined models. Independently developed loading program based on interaction of Abaqus and Matlab is used for dynamic analysis of $\mathrm{FE}$ models under different load cases, and following conclusions can be made:

(1) That predictions of FE models have well agreements with measurements proves the accuracy of FE models and feasibility of proposed simulation.

(2) A refined shell element model could accurately analyze dynamic responses of the concrete railway arch bridge in a better way than beam element and spatial grillage models due to its spatial interaction is better than another two. FEM-based analysis can be adopted for further researches of existing structures.
(3) Dynamic responses of the bridge structure don't enlarge along with the increase of train speed sometimes. For example, dynamic responses of Långforsen Bridge don't have positive correlation with train speed. Therefore, railway operation should avoid producing resonance by FEM-based analysis that eigenfrequency and excitation frequency don't come closer.

\section{Acknowledgments}

The authors gratefully acknowledge financial supp ort from both the National Natural Science Found ation of China (Project No. 51378104) and "A Proj ect Funded by the Priority Academic Program Dev elopment of Jiangsu Higher Education Institutions, PAPD", Southeast University (SEU). The first autho $r$ especially thanks the great help from Dan Xu at B eijing University of Civil Engineering and Architect ure, China as well as Shoutan Song, Jun Cheng, Do ng Yang at Southeast University, China.

\section{References}

[1] Zienkiewicz, O. C., \& Taylor, R. L. (2005). The finite element method for solid and structural mechanics. Butterworthheinemann.

[2] Schlune, H., Plos, M., \& Gylltoft, K. (2009). Improved bridge evaluation through finite element model updating using static and dynamic measurements. Engineering structures, 31(7), 1477-1485.

[3] Liu Yang, Wang Da. (2014). Theory and method for finite element analysis of bridge structures. China Communications Press.

[4] Sustainable Bridges, "Assessment for Future Traffic Demands and Longer Lives", A European FP 6 Integrated Research Project during 2003-2008. Four guidelines and 35 background documents are available at www.sustainablebridges.net: Inspection and Condition Assessment, ICA, 259 p.; Load and Resistance Assessment of Railway Bridges, LRA, 428 p.; Guideline for Monitoring of Railway Bridges, MON, 83 p.; Guide for use of Repair and Strengthening Methods for Railway Bridges, STR, $139 \mathrm{p}$. 
[5] Sanayei, M. (1997). PARIS-PARameter Identification System $\odot$. Tufts University. Medford, MA.

[6] Zhang, Q. W., Chang, T. Y. P., \& Chang, C. C. (2001). Finite-element model updating for the Kap Shui Mun cable-stayed bridge. Journal of Bridge Engineering, 6(4), 285-293.

[7] Brownjohn, J. M., \& Xia, P. Q. (2000). Dynamic assessment of curved cable-stayed bridge by model updating. Journal of Structural Engineering, 126(2), 252-260.

[8] Bell, E. S., Sanayei, M., Javdekar, C. N., \& Slavsky, E. (2007). Multiresponse parameter estimation for finite-element model updating using nondestructive test data. Journal of Structural Engineering, 133(8), 1067-1079.

[9] Grip, N., Sabourova, N., \& Tu, Y. (2016). Sensitivity-Based Model Updating for Structural Damage Identification Using Total Variation Regularization.arXiv preprint arXiv:1602.08137.

[10] Friswell, M., \& Mottershead, J. E. (1995). Finite element model updating in structural dynamics (Vol. 38). Springer Science \& Business Media.

[11] Mottershead, J. E., Link, M., \& Friswell, M. I. (2011). The sensitivity method in finite element model updating: a tutorial. Mechanical systems and signal processing, 25(7), 2275-2296.

[12] European Committee for Standardization (CEN): Euro code 1: Actions on structures, Part 2: Traffic loads on bridges. Brussels(Belgium), 2002 